\title{
REŠAVANJE SAINT-VENANT-OVOG MOMENTA TORZIJE METODOM KONAČNIH RAZLIKA
}

Andraš Zaj ${ }^{1}$

УДК: 519.6:624.071.3

DOI:10.14415/konferencijaGFS 2015.045

Rezime: Cilj ovog rada je da se numeričkom metodom rešava problem Saint-Venant-ova (čista, slobodna) torzija prizmatičnih štapova, od homogenih linearnoelastičnih materija-la. U inženjerskoj praksi možemo da sretnemo takav problem za koji nema analitičkog rešenja. U takvom slučaju za rešavanje problema moramo tražiti neki od numeričkih postupaka, jedan od tih metoda je metod konačnih razlika. Metod konačnih razlika uspešno se može primeniti na tankozidnim nosačima, na problemima plastično deformabilnih konstrukcija, zbog svoje jednostavnosti $i$ jasne veze između numerike $i$ fizičkog značenja članova u jednačinama. U radu je dato rešenje za problema torzije prizmatičnog štapa, različitog poprečnog preseka.

Ključne reči: Saint-Venant, metod konačnih razlika, parcijalna diferencijalna jednačina

\section{UVOD}

Adhemar Jean Barre de Saint-Venant, francuski naučnik [1] koji je godine 1855. u svom poznatom delu: "Mémoire sur la torsion des primes...", Mém. divers savants Acad. Sci. Paris, 14, 233-560 str., je formulisao svoj princip, koji se njemu u čast zove SaintVenant-ov princip i možemo interpretirati na sledeći način:

Ako izvesnu raspodelu površinskih spoljašnjih sila koje deluju na malom delu konture tela zamenimo nekom drugom raspodelom sila koje deluju na istom delu konture tela, tada se mahanički efekti obe raspodele neće bitno razlikovati na delovima deformabilnog tela koji su dovoljno udaljeni od mesta opterećenja, ukoliko su obe raspodele sila međusobno statički ekvivalentne.

Saint-Venant se inače smatra ocem teorije elastičnosti. Problem torzije može se podeliti na:

- slobodna, čista (Saint-Venant-ova) torzija - u svim tačkama poprečnog preseka grede javljaju se samo naponi smicanja $\tau_{z x}$ i $\tau_{z y}$,

- ograničena torzija - pored napona smicanja $\tau_{z x}$ i $\tau_{z y}$ u poprečnim presecima javljaju se i normalni naponi $\sigma_{z}$.

\footnotetext{
${ }^{1}$ Andraš Zaj, dipl. inž. građ., student, Univerzitet u Novom Sadu, Građevinski fakultet Subotica, Kozaračka 2a, Subotica, Srbija, tel: 024554 300, e - mail: andrewzay@gmail.com
} 
U ovom radu se bavimo o slobodnoj (Saint-Venant-ovoj) torziji štapa proizvoljnog poprečnog preseka, koji predstavlja specijalan slučaj dvodimenzionalne analize kontinuuma.

\section{TORZIJA GREDE PROIZVOLJNOG PUNOG POPREČNOG PRESEKA}

Koristeći Saint-Venant-ov poluobratni (semi-inverse) postupak [2,3,5] rešava se problem torzije grede čiji je presek proizvoljnog oblika.

Suština metode sastoji se u tome što, sagledavajući fizičku stranu problema, unapred predviđamo izvesne elemente analitičkog rešenja. Time smanjujemo broj nepoznatih funkcija, a eventualno i broj nezavisno promenljivih prostornih koordinata od kojih zavise nepoznate funkcije.

U matematičkoj formulaciji, ovaj problem se po metodi funkcije naprezanja opisuje Poisson-ovom parcijalnom diferencijalnom jednačinom drugog reda:

$$
\frac{\partial^{2} \phi(x, y)}{\partial x^{2}}+\frac{\partial^{2} \phi(x, y)}{\partial y^{2}}=-2 G \theta
$$

i graničnim uslovom na konturi preseka:

$$
\phi(x, y)=\text { const. }=0
$$

U ovim jednačinama $\phi(x, y)$ je Prandtl-ova funkcija napona (deplanacija), $G$ Laméova konstanta, poznata i kao modul klizanja, a $\theta=\phi^{\prime}(x, y)=d \phi(x, y) / d z$ - ugao torzije (ugao obrtanja) relativno obrtanje dva poprečna preseka na jediničnom rastojanju. Naponi smicanja $\tau_{z x}$ i $\tau_{z y}$ i momenat torizije $M_{t}$, dati su u zavisnosti od funkcije napona $\phi(x, y)$, u sledećim izrazima:

$$
\begin{aligned}
\tau_{z x} & =\frac{\partial \phi(x, y)}{\partial y} \\
\tau_{z y} & =-\frac{\partial \phi(x, y)}{\partial x} \\
M_{t} & =\iint_{F} \phi(x, y) d x d y
\end{aligned}
$$

Jednačine (1.2) imaju jednostavnu geometrijsku interpretaciju. Naime ako vrednost funkcije $\phi(x, y)$ nanesemo kao aplikate, dobićemo prostornu površ. Tada je veličina smičućeg napona jednaka nagibu tangente na površ $\phi(x, y)$ u pravcu upravnom na pravac traženog smičućeg napona, a momenat torzije je jednak dvostrukoj zapremini tela koju ova površ ograničava zajedno sa ravni poprečnog preseka.

Praktično rešavanje ovog matematičkog zadatka predstavlja složen problem, i za svaki zadati oblik konturne linije treba posebno tražiti način za njegovo rešavanje. 
Међународна конференција

Савремена достигнућа у грађевинарству 24. април 2015. Суботица, СРБИЈА

\section{METOD KONAČNIH RAZLIKA - FDM}

Metod konačnih razlika (Finite Difference Method) bazira se na matematičkoj diskretizaciji diferencijalnih jednačina prevođenjem na jednačine sa konačnim razlikama. Drugim rečima diferencijalni operator se zamenjuje odgovarajućim diferencijskim tako da umesto rešavanja parcijalne diferencijalne jednačine rešava se sistem od algebarskih linearnih (nelinearnih) jednačina, zavisno od prirode problema koji se analizira.

Mreže konačnih razlika mogu biti pravougane, trougaone, itd. U ovom radu koristićemo pravougaone mreže dimenzija $m \times n$. Posmatranu oblast ćemo podeliti vertikalnim i horizontalnim linijama i u tačkama tako dobijene mreže odredićemo vrednosti naponske funkcije $\phi(x, y)$ pri torziji. Definišemo numeričku mrežu [7] sa intervalima širine $\Delta x \mathrm{u}$ smeru ose $x$, te širine $\Delta y$ u osi $y$.

a) pravilan rub domena

Aproksimacije parcijalnih derivacija pomoću metode konačnih razlika su za ovako definisane oznake jednake:

$$
\begin{aligned}
& \frac{\partial^{2} \phi}{\partial x^{2}} \cong \frac{\phi_{i+1, j}-2 \phi_{i, j}+\phi_{i-1, j}}{\Delta x^{2}} \\
& \frac{\partial^{2} \phi}{\partial y^{2}} \cong \frac{\phi_{i, j+1}-2 \phi_{i, j}+\phi_{i, j-1}}{\Delta y^{2}}
\end{aligned}
$$

Tako da je diskretizacija Poasson-ove parcijalne diferencijalne jednačine drugog reda (1.1) za pravilan rub domena ima oblika:

$$
\frac{1}{\Delta x^{2}}\left(\phi_{i+1, j}-2 \phi_{i, j}+\phi_{i-1, j}\right)+\frac{1}{\Delta y^{2}}\left(\phi_{i, j+1}-2 \phi_{i, j}+\phi_{i, j-1}\right)=-2 G \theta
$$

\section{b) nepravilan rub domena}

U ovom slučaju ne možemo primeniti prethodne jednačine (1.3), jer neke od tačaka koje se pojavljuju u toj jednačini ne leže niti unutar niti na rubu posmatranog područja. Umesto toga iskoristimo poznate vrednosti, iz razvoja funkcije $\phi(x, y)$ u Taylorov red sledi aproksimacija druge parcijalne derivacije po $x$ u tačku $(i, j)$ :

$$
\frac{\partial^{2} \phi}{\partial x^{2}} \cong \frac{2}{\Delta x^{2}}\left(\frac{1}{a(1+a)} \phi_{i-1, j}+\frac{1}{1+a} \phi_{i+1, j}-\frac{1}{a} \phi_{i, j}\right)
$$

Na sličan način se dobije i aproksimacija:

$$
\frac{\partial^{2} \phi}{\partial y^{2}} \cong \frac{2}{\Delta y^{2}}\left(\frac{1}{b(1+b)} \phi_{i, j-1}+\frac{1}{1+b} \phi_{i, j+1}-\frac{1}{b} \phi_{i, j}\right)
$$

Uvrštavanjem dobijenih aproksimacija sledi da kod nepravilnog ruba domena, za tačke koje se nalaze u blizini ruba, diskretizacija Poasson-ove jednačine (1.1) ima oblik:

$$
\frac{2}{\Delta x^{2}}\left(\frac{1}{a(1+a)} \phi_{i-1, j}+\frac{1}{1+a} \phi_{i+1, j}-\frac{1}{a} \phi_{i, j}\right)+\frac{2}{\Delta y^{2}}\left(\frac{1}{b(1+b)} \phi_{i, j-1}+\frac{1}{1+b} \phi_{i, j+1}-\frac{1}{b} \phi_{i, j}\right)=-2 G \theta
$$




\section{$41^{\text {th }}$}

International conference

Contemporary achievements in civil engineering 24. April 2015. Subotica, SERBIA

gde su $a \cdot \Delta x$ i $b \cdot \Delta y$ udaljenosti tačaka na rubu domena od tačke $(i, j)$, tako da je $0<a$ i $b<1$ respektivno.

Kada se odrede vrednosti funkcije naprezanja u čvorovima mreže $\phi_{(i, j)}$, mogu se izračunati komponente naprezanja u svakom čvoru mreže, torzijska krutost preseka, trajektorije naprezanja i sl.

\section{NUMERIČKI PRIMERI}

a) Primer 1 .

Osnovnu ideju metode konačnih razlika i njenu realizaciju prikazaćemo na primerima rešavanja St. Venant-ove torzije prizmatičnih štapova. Za numerički primer korišćen je Primer 5.3.11. str. 209. iz knjige [3] Sekulović, M. Metod Konačnih Elemenata.

Za štap kvadratnog poprečnog preseka $a=b=1.0$, koji je izložen slobodnoj torziji, treba odrediti promenu naponske funkcije i smičućih napona po preseku.

Rešenje:
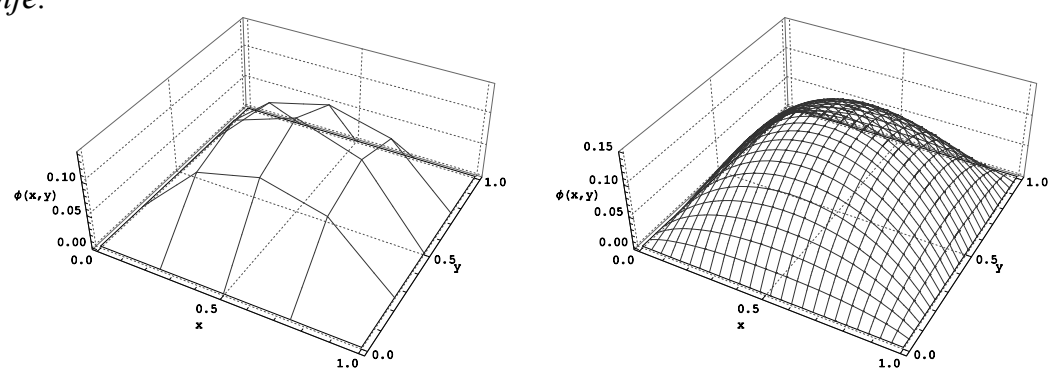

Slika 1 - diskretizacija domena, (Prandtl-ova) funkcija naprezanja $\phi(x, y)$

(deplanacije) pri različitoj gustini mreže
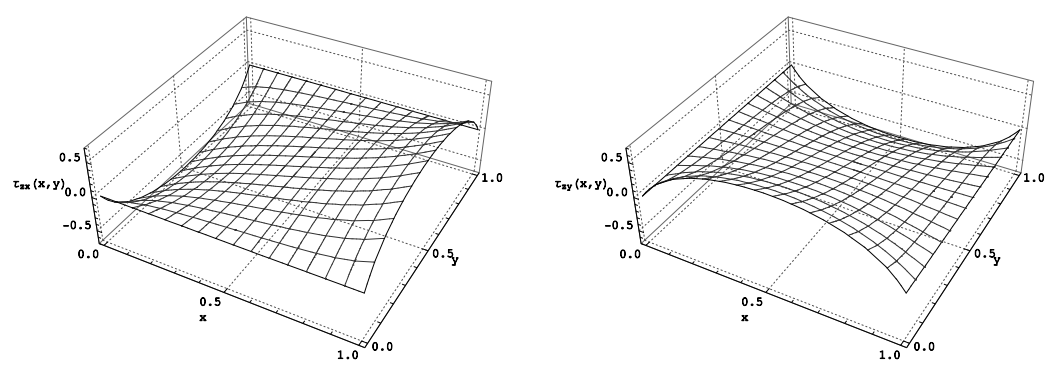

Slika 2 - dijagram napona smicanja $\tau_{z x} i \tau_{z y}$ 

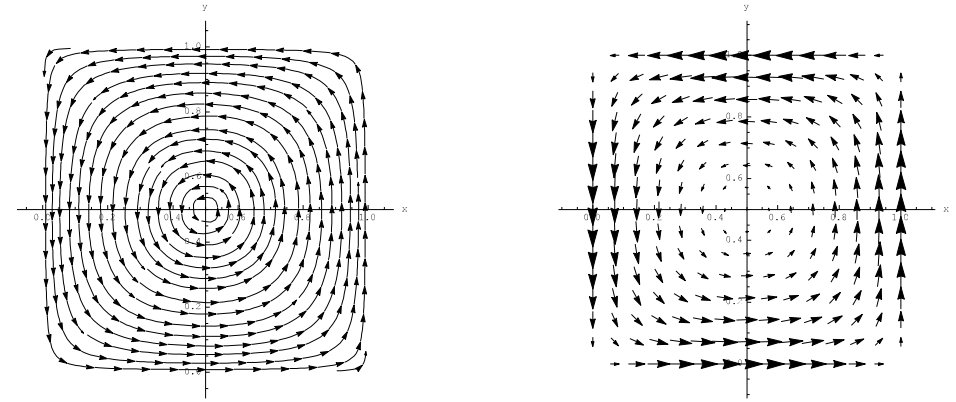

Slika 3 - trajektorija napona i vektorski dijagram raspodele napona smicanja $\tau_{z x}$ i $\tau_{z y}$ pri čistoj torziji

b)

Primer 2.

Za štap kružnog poprečnog preseka $R=1.0$, koji je izložen slobodnoj torziji, treba odrediti promenu naponske funkcije i smičućih napona po preseku.

Rešenje:
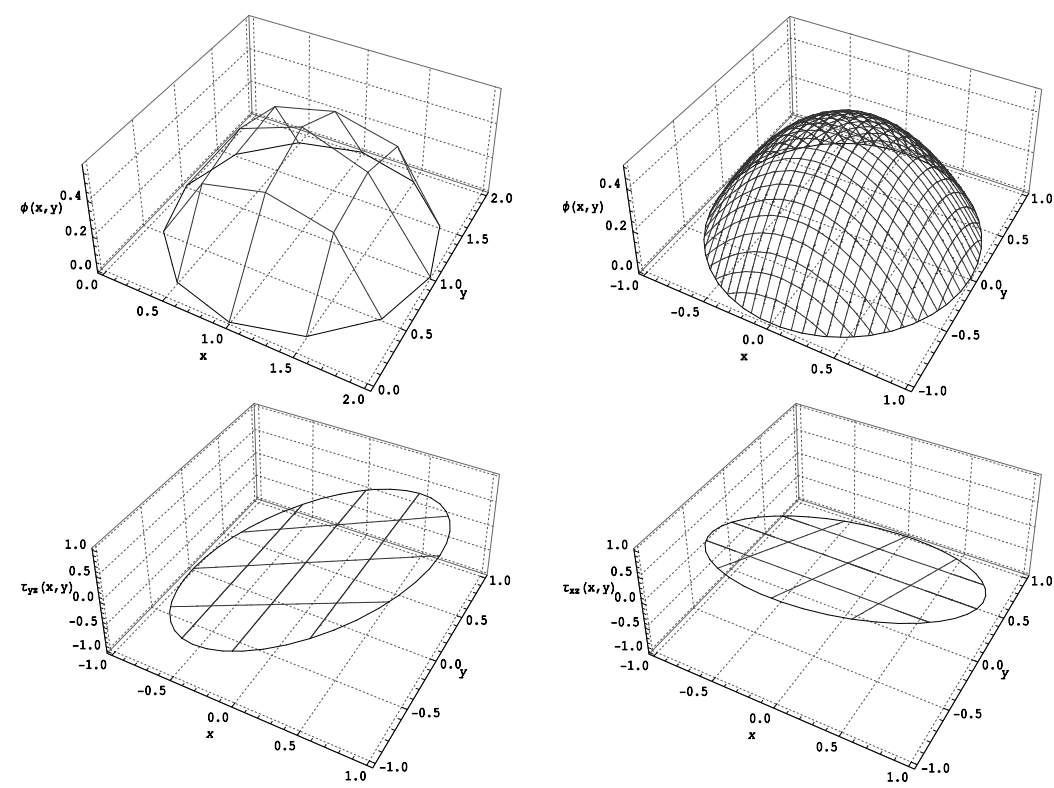

Slika 4 - diskretizacija domena, (Prandtl-ova) funkcija naprezanja $\phi(x, y)$ (deplanacije) pri različitoj gustini mreže $i$ dijagram napona smicanja $\tau_{z x} i \tau_{z y}$ 


\section{$41^{\text {th }}$ ANNIVERSARY FACULTY OF CIVIL ENGINEERING SUBOTICA}

International conference

Contemporary achievements in civil engineering 24. April 2015. Subotica, SERBIA
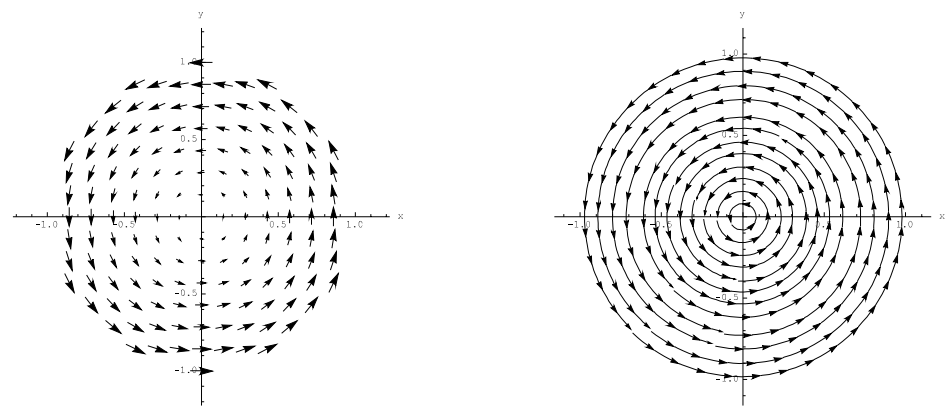

Slika 5 - trajektorija napona i vektorski dijagram raspodele napona smicanja $\tau_{z x}$ i $\tau_{z y}$ pri čistoj torziji
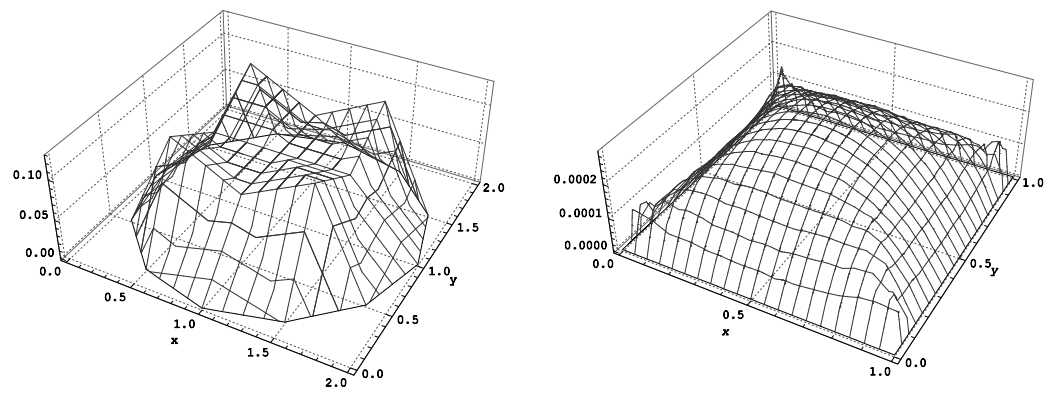

Slika 6-apsolutna greška metoda FDM za različite poprečni presek

Prilikom proračuna možemo primetiti (Slika 6.) da su rezultati dobijeni metodom konačnih razlika za kvadratni poprečni presek već pri maloj gustini mreže $m \times n=3 \times 3$ prilično tačni i da je apsolutna greška proračuna za funkcijski napona $\approx 2.58 \%$. Dok rezultat dobijen na nepravilnom rubu domena, (kružni poprečni presek) već ima znatnih odstupanja pri maloj gustini mreže $m \times n=3 \times 3$, naročito u blizini ruba domena oko $\approx 16.99 \%$ u odnosu na tačno rešenje.

\section{ZAKLJUČAK}

Osnovna prednost postupka konačnih razlika je njegova jednostavnost i tačnost u slučaju kada su granični uslovi korektno opisani. Glavni nedostatak je ograničena mogućnost opisivanja nepravilnih delova ruba područja. Efikastnost metode opada sa povećanjem broja čvornih tačaka. 
Међународна конференција

Савремена достигнућа у грађевинарству 24. април 2015. Суботица, СРБИЈА

\section{LITERATURA}

[1] Dunica, Š.: Otpornost materijala, Građevinski Fakultet, Beograd, 1995.

[2] Sekulović, M.: Metod konačnih elemenata, Građevinska Knjiga, Beograd, 1984.

[3] Naerlović-Veljković, N., Pavšić, M: Teorija elastičnosti, Naučna Knjiga, Beograd, 1980.

[4] Brčić, V.: Otpornost materijala, Građevinska Knjiga, Beograd, 1978.

[5] Dž. T. Katsikadelis: Granični elementi teorija i primene, Građevinska Knjiga, Beograd, 2011.

[6] Prokić, A.: Matrična analiza tankozidnih konstrukcija, Izgradnja, Beograd, 1999.

[7] Internet:

http://www.gradst.hr/Portals/9/PropertyAgent/1167/Files/3760/Torzija.pdf, 2015

\section{SOLUTION OF THE SAINT-VENANT'S TORSION WITH FINITE DIFFERENCE METHOD}

Summary: The goal of this work is the numerical solving of Saint-Venant's (pure, uniform) torsion on prismatic beams made up from homogeneous, linearly elastic material. In engineering practice we can find this problem but there is no analitycal solving method or just a very complicated one. For solving this problem we have to search a numerical method, and one of these is finite difference method. Finite difference method can be successfully used on thin-walled structural members, on problems with plastically deformable contructions, because of its simplicity and clear connection between numerics and physical meaning of members in equations. In the work is given the solution for torsion problem of prismatic beam, with different cross sections. Numerical solving of problem is made with Wolfram Mathematica.

Keywords: Saint-Venant, finite difference method, partial differential equations 